\title{
5.15 Left Ventricular Patterns in a Population of a Hypertension
}

Centre Echolab

D. Degli Esposti (1), A. Dormi (1), S. Bacchelli (1), E.R. Cosentino (1), F. Santi (1),

E.R. Rinaldi (1), M. Rosticci (1), M. Pombeni (1), D. Maione (1), E. Tartagni (1),

M. Veronesi (1), C. Borghi (1)

(1)Sant'Orsola - Malpighi, Università di Bologna, Bologna, Italy

Introduction. Left ventricular (LV) hypertensive modifications are usually classified in 4 different patterns with different prognosis. Increasing in LV mass (LVM) and/or relative wall thickness (RWT) characterize the $4 \mathrm{LV}$ patterns. Normal geometry (NG) is defined by normal LVM and RWT, concentric remodelling (CR) by the increase of only RWT, eccentric hypertrophy (EH) by the increase of only LVM, and concentric hypertrophy $(\mathrm{CH})$ by the increase of both LVM and RWT.

Aim. To evaluate the prevalence of these aspects of organ damage in subjects submitted to echocardiography in a hypertension centre echolab.

Methods. In two years (2005-2007) we evaluated 1608 consecutive patients submitted to an echocardiography (M 761, F 847, mean age 63.29 years, range 11-93), with assessment of LVM, indexed to body surface area (BSALVM) and to height 2.7 (HLVM), and RWT [(interventricular septum + posterior wall)/end diastolic left ventricular diameter]

Results. Of these subjects, $1108(68.9 \%)$ had a history of hypertension $(\mathrm{H})(\mathrm{H}$ mean age 67.46 years, Not $\mathrm{H}$ mean age 54.07 years, $\mathrm{p}<0.0001)$ [table I]. Globally, an increased BSALVM, HLVM $(>125 \mathrm{~g} /$ $\mathrm{m} 2$ or $>49.2 \mathrm{~g} / \mathrm{h} 2.7$ in men, and $>110 \mathrm{~g} / \mathrm{m} 2$ or $>46.7 \mathrm{~g} / \mathrm{m} 2.7$ in women) and RWT $(>0.45)$ has been observed in $30 \%, 48.6 \%$, and $46.3 \%$ of cases. An increased BSALVM,HLVN and RWT was also observed in $36.6 \%, 60.5 \%$, and $56.3 \%$ of $\mathrm{H}$ and in $15.2 \%, 22.2 \%$ and $24 \%$ of subjects without $\mathrm{H}$ or any other cause of increased wall thickness or LV dimensions (Not $\mathrm{H}$ ), obviously with significant differences between $\mathrm{H}$ and Not $\mathrm{H}$. In the table, the LV patterns in $\mathrm{H}$, Not $\mathrm{H}$ and global population (Tot), respect to the two different LVM indexation systems $(*=\mathrm{p}<0.0001 \mathrm{vs} \mathrm{H})$.

\begin{tabular}{lllll} 
& NG $(\%)$ & CR $(\%)$ & EH $(\%)$ & CH $(\%)$ \\
\hline Noth & & & & \\
Mls & 68.8 & 16 & 7.2 & 8 \\
Mlh & 66 & 11.8 & 10 & 12.2 \\
H & & & & \\
Mls & 32.2 & 31.1 & 11.5 & 25.2 \\
Mlh & 19.9 & 19.6 & 23.7 & 36.7 \\
Tot & & & & \\
Mls & 43.6 & 26.4 & 10.1 & 19.8 \\
Mlh & 34.3 & 17.2 & 19.5 & 29.1 \\
\hline
\end{tabular}

Conclusions. The most frequently observed geometries in $\mathrm{H}$ were the concentric ones. However, modifications suggesting a possible hypertensive damage were observed even in subjects without hypertension or other causes of myocardial damage, as a possible expression of unknown hypertension, and suggesting therefore how hypertension diagnosis is still insufficiently performed and how instrumental tools are sometimes preferred to effective and less expensive clinical diagnostic tools to identify an easily and, on the contrary, well clinically identifiable disease such as hypertension. 